\title{
Quercetin decreases high-fat diet induced body weight gain and accumulation of hepatic and circulating lipids in mice
}

\author{
E. F. Hoek-van den Hil • E. M. van Schothorst $\cdot$ I. van der Stelt \\ H. J. M. Swarts · D. Venema - M. Sailer · J. J. M. Vervoort • \\ P. C. H. Hollman · I. M. C. M. Rietjens · J. Keijer
}

Received: 11 June 2014/ Accepted: 7 July 2014/Published online: 22 July 2014

(C) Springer-Verlag Berlin Heidelberg 2014

\begin{abstract}
Dietary flavonoids may protect against cardiovascular diseases (CVD). Increased circulating lipid levels and hepatic lipid accumulation are known risk factors for CVD. The aim of this study was to investigate the effects and underlying molecular mechanisms of the flavonoid quercetin on hepatic lipid metabolism in mice with high-fat diet induced body weight gain and hepatic lipid accumulation. Adult male mice received a 40 energy $\%$ high-fat diet without or with supplementation of $0.33 \%(w / w)$ quercetin for 12 weeks. Body weight gain was $29 \%$ lower in quercetin fed mice $(p<0.01)$, while the energy intake was not significantly different. Quercetin supplementation lowered hepatic lipid accumulation to $29 \%$ of the amount
\end{abstract}

Electronic supplementary material The online version of this article (doi:10.1007/s12263-014-0418-2) contains supplementary material, which is available to authorized users.

E. F. Hoek-van den Hil · E. M. van Schothorst ( $)$.

I. van der Stelt · H. J. M. Swarts · J. Keijer

Human and Animal Physiology, Wageningen University,

De Elst 1, 6708 WD Wageningen, The Netherlands

e-mail: evert.vanschothorst@wur.nl

E. F. Hoek-van den Hil · D. Venema · P. C. H. Hollman

RIKILT, Wageningen UR, Wageningen, The Netherlands

E. F. Hoek-van den Hil - I. M. C. M. Rietjens

Division of Toxicology, Wageningen University, Wageningen,

The Netherlands

M. Sailer

Molecular Nutrition Unit, Research Center for Nutrition

and Food Sciences, Technische Universität München,

Freising-Weihenstephan, Germany

J. J. M. Vervoort

Laboratory of Biochemistry, Wageningen University,

Wageningen, The Netherlands present in the control mice $(p<0.01) .{ }^{1} \mathrm{H}$ nuclear magnetic resonance serum lipid profiling revealed that the supplementation significantly lowered serum lipid levels. Global gene expression profiling of liver showed that cytochrome $\mathrm{P} 450$ 2b (Cyp2b) genes, key target genes of the transcription factor constitutive androstane receptor (Car; official symbol Nrli3), were downregulated. Quercetin decreased high-fat diet induced body weight gain, hepatic lipid accumulation and serum lipid levels. This was accompanied by regulation of cytochrome $\mathrm{P} 450 \mathrm{2b}$ genes in liver, which are possibly under transcriptional control of CAR. The quercetin effects are likely dependent on the fat content of the diet.

Keywords Bioactive food component - Flavonoid · Gene expression profiling - Hepatic lipid accumulation - Lipid metabolism

$\begin{array}{ll}\text { Abbreviations } \\ \text { Acot3 } & \text { Acyl-CoA thioesterase 3 } \\ \text { B2m } & \text { Beta-2 microglobulin } \\ \text { Car } & \text { Constitutive androstane receptor } \\ \text { Csad } & \text { Cysteine sulphinic acid decarboxylase } \\ \text { CVD } & \text { Cardiovascular diseases } \\ \text { Cyp } & \text { Cytochrome P450 } \\ \text { En\% } & \text { Energy\% } \\ \text { Fabp5 } & \text { Fatty acid binding protein 5 } \\ \text { FA } & \text { Fatty acids } \\ \text { Hao2 } & \text { Hydroxyacid oxidase 2 } \\ \text { HOMA-IR } & \begin{array}{l}\text { Homoeostasis model assessment-insulin } \\ \text { resistance }\end{array} \\ \text { Hprt1 } & \text { Hypoxanthine phosphoribosyltransferase 1 } \\ \text { Por } & \text { Cytochrome P450 oxidoreductase } \\ \text { RT-qPCR } & \begin{array}{l}\text { Real-time quantitative polymerase chain } \\ \text { reaction }\end{array}\end{array}$




\section{Introduction}

High consumption of fruits and vegetables is protective against cardiovascular diseases (CVD) (van't Veer et al. 2000). Flavonoids in fruits and vegetables are suggested to contribute to these protective effects (Mink et al. 2007). Moreover, epidemiological studies have shown that the intake of the flavonoid quercetin is associated with a reduction of CVD risk (Arts and Hollman 2005; Hertog et al. 1993; Hollman et al. 2010). In the Western diet, quercetin is the major dietary flavonol, a subclass of the flavonoids, and is present in, for example, apples, tea, red wine, and onions. Our previous results in mice showed that a quercetin supplemented mild high-fat diet increased hepatic lipid metabolism, especially omega $(\omega)$-oxidation, and reduced corresponding circulating lipid levels (Hoekvan den Hil et al. 2013). The cardiovascular protective properties of quercetin might therefore be explained by the lipid lowering effect of quercetin, since increased circulating levels of free fatty acids and triglycerides are known risk factors for CVD (Boden 2008; Harchaoui et al. 2009; Jouven et al. 2001). Furthermore, growing evidence shows that increased lipid accumulation in the liver also increased the risk of CVD (Scorletti et al. 2011; Targher et al. 2010).

The mechanisms behind these effects of quercetin are neither fully understood nor conclusive. Other rodent studies with quercetin supplementation that investigated lipid lowering effects showed reduction in body weight, serum lipid levels, hepatic lipid accumulation, and/or white adipose tissue mass. However, these effects were not seen in all studies and were sometimes conflicting (de Boer et al. 2006; Hoek-van den Hil et al. 2013; Jung et al. 2013; Kobori et al. 2011; Odbayar et al. 2006; Stewart et al. 2009; Wein et al. 2010). It is not clear which combination of factors, like dose of quercetin, dietary en $\%$ of fat or duration causes these effects on lipids. Previously, we have observed an effect of quercetin on serum lipid lowering and hepatic lipid $\omega$-oxidation using a mild high-fat diet (30 en\%) for 12 weeks (Hoek-van den Hil et al. 2013). Here, we examined whether the same effects would be observed using the same amount of quercetin and the same duration, but using a high-fat diet (40 en\%), which is expected to induce body weight gain as well as hepatic lipid accumulation. This high-fat diet is a fully standardised diet with a fatty acid composition that provides a balance of essential fatty acids and a healthy polyunsaturated to saturated ratio (Voigt et al. 2013). The main focus was on the effects of quercetin on hepatic lipid metabolism, since the liver is the major effector organ of lipid metabolism. We assessed hepatic lipid accumulation and profiled serum lipids. Based on previous results, expression of genes involved in $\omega$-oxidation was studied. In addition, we performed whole genome gene expression analysis to obtain an overview of the molecular changes induced by quercetin on this dietary background.

\section{Materials and methods}

Animals and treatments

Twenty-four male C57BL/6JOlaHsd mice (Harlan Laboratories, Horst, the Netherlands) were individually housed and maintained under environmentally controlled conditions (temperature $21{ }^{\circ} \mathrm{C}, 12 \mathrm{~h} / 12 \mathrm{~h}$ light-dark cycle, $55 \pm 15 \%$ humidity), with ad libitum access to food and water. At arrival, the mice were 9 weeks old and were adapted for 3 weeks. The first 5 days of adaptation were on standard chow diet, which was followed by a standardised semi-synthetic normal fat diet (10 en\% fat) with the same dietary constituents as the control high-fat diet (Voigt et al. 2013) (Research Diets Services B.V., Wijk bij Duurstede, the Netherlands; supplementary table S1). During the intervention, the mice $(n=12)$ received high-fat diet (40 en $\%$ fat) without or with supplementation of $0.33 \%(w / w)$ quercetin (Sigma, Zwijndrecht, the Netherlands). The percentage of quercetin in the diet was identical to that used in our previous study (Hoek-van den Hil et al. 2013). Body weight and food intake of individual mice were weekly monitored. Faeces were collected in weeks 11 and 12 ( $n=4)$. One quercetin fed mouse was excluded from all analyses, because a nasal abscess developed in week 6 . After 12 weeks of intervention, all mice were fasted for 2-4 h during the light phase and anesthetized by inhalation of $5 \%$ isoflurane using $\mathrm{O}_{2}$ as a carrier. Blood was sampled via orbital extraction in collect serum tubes (Greiner Bioone, Longwood, USA), kept on ice for max $2 \mathrm{~h}$, and centrifuged for $10 \mathrm{~min}$ at $3,000 \mathrm{~g}$ at $4{ }^{\circ} \mathrm{C}$ to obtain serum, aliquoted, and stored at $-80{ }^{\circ} \mathrm{C}$. After blood collection, mice were killed by cervical dislocation, and liver was dissected, weighted and snap frozen in liquid nitrogen and stored at $-80{ }^{\circ} \mathrm{C}$. The experiment was performed according to the Dutch Animal Experimentation Act (1996), and the experimental protocol was approved by the Animal Welfare Committee of Wageningen University, Wageningen, the Netherlands (DEC 2011079).

\section{Energy content of faeces and diet}

Bomb calorimetry was used to determine energy content of diet and faeces $(n=4)$ (Calorimeter C7000, IKA, Staufen, Germany). Measured faecal energy content was extrapolated to calculate with the measured dietary energy content and the weekly measured food intake the total digestible 
energy intake over 12 weeks. Digestible energy intake is assumed to be comparable with metabolisable energy intake, as dietary protein content is equal for both diets and no differences in urinary energy losses were expected.

HPLC analysis of quercetin levels in serum

Quercetin levels in serum $(n=6)$ were measured using HPLC with coulometric array detection as described (Hoek-van den Hil et al. 2013). Before analysis, samples were hydrolysed by $\beta$-glucuronidase/sulphatase to obtain deconjugated quercetin, isorhamnetin and tamarixetin.

Serum and tissue lipid measurements

Because quercetin was previously shown to interfere with commonly used commercially available enzymatic lipid assays (Hoek-van den Hil et al. 2012), alternative methods were used. Neutral lipids were stained in frozen liver sections $(n=6)$ with Oil red O (Sigma) and quantified as described (Hoek-van den Hil et al. 2013). Ten to 16 pictures per animal were quantified $(n=6)$. Serum lipids were extracted and analysed with ${ }^{1} \mathrm{H}$ nuclear magnetic resonance ( $\left.{ }^{1} \mathrm{H}-\mathrm{NMR}\right)$ as described (Hoek-van den Hil et al. 2013).

Serum insulin levels were quantified by sandwich-type ELISA (Shibayagi Co., Ltd., Gunma, Japan) and blood glucose levels using ADC Freestyle blood glucose system (Abbott Diabetes Care, Hoofddorp, the Netherlands). The homoeostasis model assessment-insulin resistance (HOMA-IR) was calculated using the following formula: fasting plasma insulin $(\mathrm{mIU} / \mathrm{l}) \times$ fasting glucose $(\mathrm{mmol} / \mathrm{l}) /$ 22.5. Taurine levels in serum and hepatic tissues were quantified as described (Sailer et al. 2013) using the aTRAQ $^{\circledR}$ reagent (aTRAQ ${ }^{\mathrm{TM}}$ Reagent Kit, ABSciex, Foster City, USA).

Real-time quantitative polymerase chain reaction (RT-qPCR)

RNA from liver was isolated using RNeasy columns (Qiagen, Venlo, the Netherlands) and used for RT-qPCR and microarray analysis. RNA purity and quality was verified using a Nanodrop spectrophotometer (IsoGen Life Science, Maarsen, the Netherlands) and on Experion automated electrophoresis system (Bio-Rad, Veenendaal, the Netherlands). RT-qPCR was performed as previously described (Hoek-van den Hil et al. 2013) according to the MIQE guidelines (Bustin et al. 2009). Data were normalised against reference genes beta- 2 microglobulin $(B 2 m)$ and hypoxanthine phosphoribosyltransferase 1 (Hprtl) which were chosen based on stable gene expression levels (geNorm, Ghent University Hospital, Ghent, Belgium).
Sequences of the used primers can be found in supplementary table $\mathrm{S} 2$.

Microarray analysis

For global transcriptome analysis, liver samples of individual mice and $8 \times 60 \mathrm{~K}$ Agilent whole-mouse genome microarrays (G4852A, Agilent Technologies Inc., Santa Clara, CA) were used according to the manufacturer's protocol with a few modifications as described previously (van Schothorst et al. 2007). cDNA was synthesised for each animal from 200 ng RNA. Normalisation and data analysis were performed as published (Pellis et al. 2003) using Feature Extraction version 10.7.3.1 (Agilent Technologies). Based on visual inspection, three arrays were excluded in which hybridization was not homogenous. Fold change was expressed as ratio of quercetin group $(n=10)$ versus control group ( $n=11)$. Pathway analysis was performed using MetaCore (GeneGo, St. Joseph, Michigan, USA). Microarray data have been deposited in NCBI Gene Expression Omnibus under accession number GSE51343.

Statistical analysis

GraphPad Prism version 5.03 (Graphpad Software, San Diego, USA) was used for statistical analysis, with Student's $t$ test being used to compare the two groups if normally distributed. Two-way ANOVA (repeated measures, matched values) followed by a Bonferroni post hoc test was used for body weight in time analysis. Two-way ANOVA (no repeated measures) was used for analysis of the lipid profiles in serum. $P$ values smaller than 0.05 were considered significantly different.

\section{Results}

Quercetin lowered high-fat diet induced body weight gain and food efficiency

Mice received a 40 en\% high-fat diet without (control) or with supplementation of quercetin for 12 weeks. Body weight of the mice was significantly lower upon quercetin supplementation compared to the high-fat diet from week 7 onwards (Fig. 1a). Total body weight gain after 12 weeks was $29 \%$ lower in the quercetin fed mice compared to the control mice ( $p<0.01$; Fig. 1b), while digestible (equals metabolisable) energy intake over 12 weeks was not significantly different (Fig. 1c). Consequently, the calculated food efficiency was $26 \%$ lower for the quercetin fed mice $(p<0.001)$ (Fig. 1d). The weekly food intake and energy content of faeces used for the calculation is provided in supplementary figure S1. 

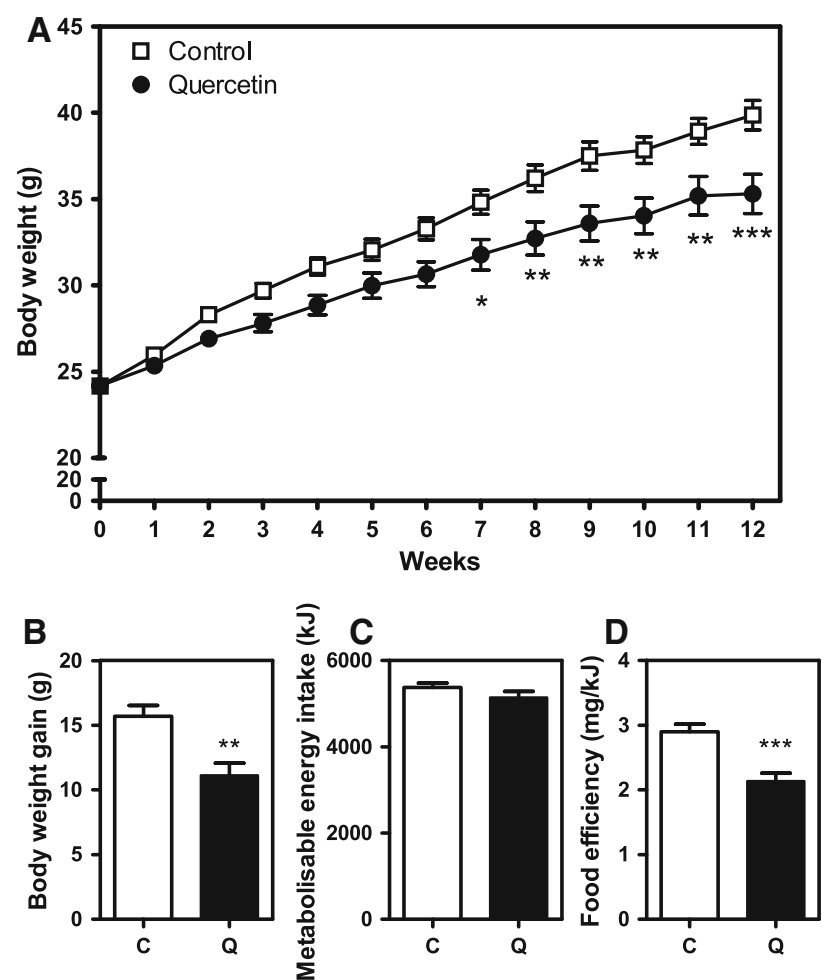

Fig. 1 Quercetin reduces body weight gain and food efficiency. Body weight of control $(n=12)$ and quercetin $(n=11)$ fed mice during 12 weeks on high-fat diet (a). Cumulative body weight gain over 12 weeks (b). Cumulative metabolisable energy intake over 12 weeks (c). Calculated total food efficiency in body weight gain per $\mathrm{kJ}$ consumed (d). Data are presented as mean \pm SEM. White bars indicate the control group (c) and black bars indicate the quercetin group (Q). Asterisks indicates a significant difference between both groups, ${ }^{*} p<0.05, * * p<0.01, * * * p<0.001$

\section{Concentration of quercetin in serum}

The sum of quercetin and isorhamnetin after deconjugation in serum was $6.5 \pm 1.4 \mu \mathrm{M}$ (quercetin $2.8 \pm 1.4 \mu \mathrm{M}$, isorhamnetin $3.7 \pm 0.8 \mu \mathrm{M}$, and no tamarixetin was found). No quercetin was found in serum of control animals. The calculated quercetin intake based on the food intake of the quercetin fed mice was $\sim 325 \mathrm{mg} \mathrm{kg}^{-1}$ body weight day $^{-1}$.

Quercetin decreased high-fat diet induced serum and hepatic lipid levels

Because quercetin was previously shown to interfere with many commercially available enzymatic assays including the ones commonly used for measurement of serum and hepatic lipids (Hoek-van den Hil et al. 2012), we quantified various serum lipid fractions with ${ }^{1} \mathrm{H}$ NMR and hepatic lipid accumulation with histological Oil red $\mathrm{O}$ staining.

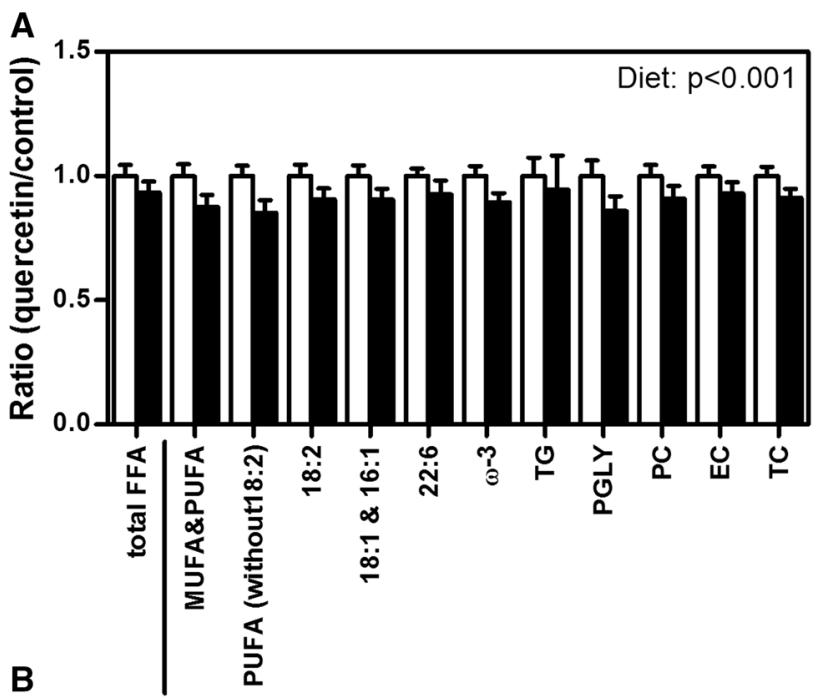

Control

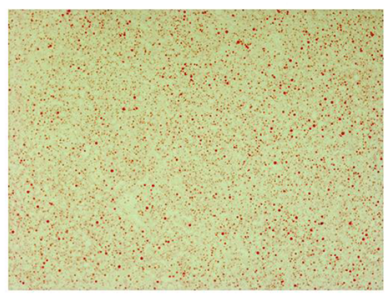

Quercetin

C

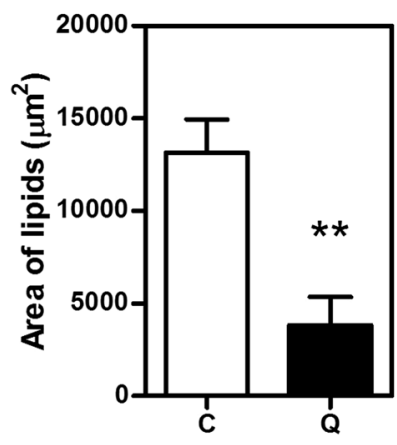

D

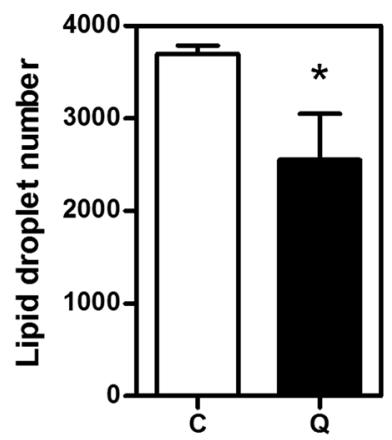

Fig. 2 Quercetin decreased high-fat diet induced serum lipid levels and hepatic lipid accumulation. a Serum lipid fractions are shown as ratio of quercetin fed mice $(n=11)$ over the average value of the control mice $(n=12)$. Two-way ANOVA; diet significant $(p<0.01)$. b Representative pictures of hepatic lipid staining with Oil red $\mathrm{O}$ for control and quercetin fed mice on a high-fat diet $(n=6)$. Quantification of mean total area of lipids per picture $(\mathbf{c})$ and mean lipid droplet number per picture (d). Data are presented as mean \pm SEM. White bars indicate the control group $(C)$ and black bars indicate the quercetin group $(Q)$. Asterisks indicate a significant difference between both groups, $* p<0.05$, $* * p<0.01$. PUFA poly unsaturated fatty acids, $M U F A$ mono unsaturated fatty acids; $F A$ fatty acids, $T G$ triglycerides, $P G L Y$ phosphoglycerides, $P C$ phosphatidylcholine, EC esterified cholesterol, $T C$ total cholesterol

Two-way ANOVA analysis revealed that quercetin supplementation has a significant lowering effect on the highfat diet induced serum lipid levels (Fig. 2a). 
Table 1 Gene expression of genes related with lipid $\omega$-oxidation measured with RT-qPCR in liver

\begin{tabular}{lllll}
\hline $\begin{array}{l}\text { Gene } \\
\text { symbol }\end{array}$ & Gene name & $\begin{array}{l}\text { Accession } \\
\text { number }\end{array}$ & \multicolumn{2}{l}{ RT-qPCR } \\
\cline { 5 - 6 } & & FC & $p$ \\
\hline $\begin{array}{l}\text { Acot3 } \\
\text { Cyp4a10 }\end{array}$ & $\begin{array}{c}\text { Acyl-CoA thioesterase } 3 \\
\text { Cytochrome P450, } \\
\text { family 4a10 }\end{array}$ & NM_134246 & 1.07 & 0.68 \\
Cyp4a14 & $\begin{array}{c}\text { Nytochrome P450, } \\
\text { family 4a14 }\end{array}$ & NM_007821 & -1.09 & 0.82 \\
Por & $\begin{array}{c}\text { P450 (cytochrome) } \\
\text { oxidoreductase }\end{array}$ & NM_008898 & 1.11 & 0.47 \\
\cline { 5 - 6 }
\end{tabular}

Fold changes are depicted as the expression values of quercetin over control animals

$F C$ fold change; $p p$ value

Relative liver weight was not significantly different between both groups. Oil red $\mathrm{O}$ stained liver sections showed that hepatic lipid accumulation in quercetin fed mice was significantly lower amounting to $29 \%$ (measured as area) of the value observed for control mice fed the highfat diet, and lipid droplet number in the quercetin fed mice was $69 \%(p<0.05)$ of the value observed in control mice (Fig. 2).

Serum insulin $(0.60 \pm 0.46$ and $0.98 \pm 0.58 \mathrm{ng} / \mathrm{ml}$, resp.), blood glucose $(8.4 \pm 1.2$ and $9.1 \pm 0.7 \mathrm{mM}$, resp.) and calculated HOMA-IR $(5.9 \pm 4.8$ and $10.5 \pm 6.8$, resp.) were not significantly different between the quercetin and the control group.

\section{Quercetin regulated hepatic gene expression}

First, hepatic expression levels of genes involved in $\omega$ oxidation, identified in our previous study where quercetin was supplemented to a mild high-fat diet (Hoek-van den Hil et al. 2013), were studied. However, RT-qPCR analysis indicated no significant regulation of Cyp4a14, Cyp4a10, Acot3, nor Por (Table 1).

Subsequently, we profiled gene expression in the liver using whole genome microarrays, since we observed large differences in hepatic lipid accumulation between the two groups. Of the 34,373 probes showing expression, 462 probes showed differential expression upon quercetin supplementation to a high-fat diet as compared to the highfat diet alone $(p<0.01)$. Similar to RT-qPCR, microarrays did not show regulation of the $\omega$-oxidation-related genes. Pathway analysis of the differentially expressed genes revealed no reliable regulated pathways. In the volcano plot, four major regulated genes (absolute fold change $>2.0$ with $p<0.01$ ) were observed (Fig. 3). Cysteine sulphinic acid decarboxylase (Csad), encoding the rate limiting enzyme in taurine biosynthesis, was upregulated with a fold change of 2.3. However, taurine levels in

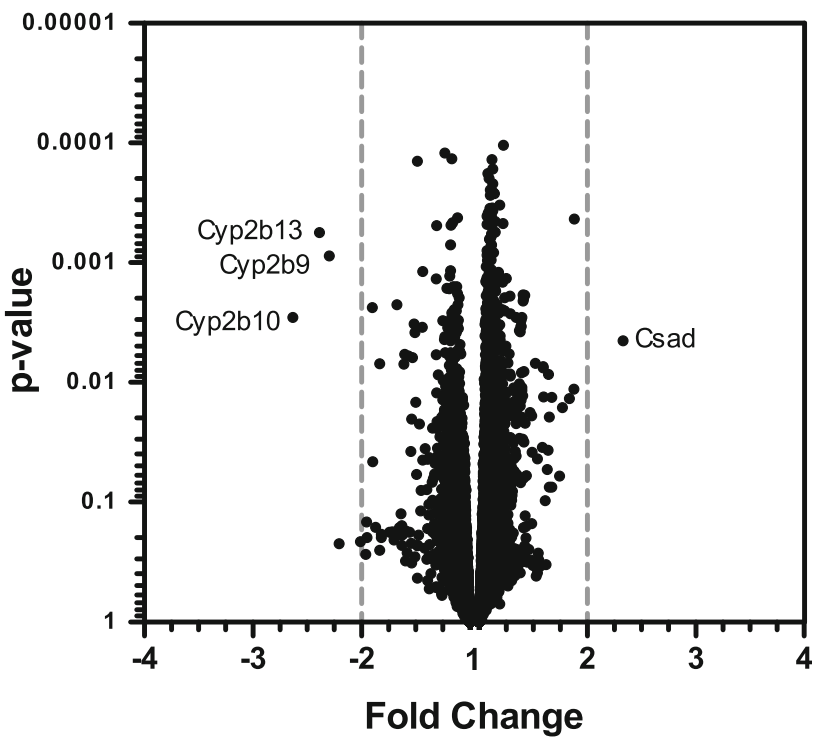

Fig. 3 Volcano plot of all expressed probes by global hepatic gene expression analysis. $P$ values of all probes are plotted against the fold change of each probe, quercetin $(n=10)$ versus control $(n=11)$. Dotted lines indicate used cut-off value of an absolute fold change $>2.0$. Selected gene symbols are depicted in the figure; cytochrome P450 (Cyp) enzymes Cyp2c9, Cyp2c10, and Cyp2c13, and cysteine sulphinic acid decarboxylase (Csad)

serum and in hepatic tissue were not significantly affected by the quercetin diet (supplementary table S3).

Three cytochrome P450 enzyme encoding genes, Cyp2b9, Cyp2b10, and Cyp2b13, were all downregulated with fold changes between -2.3 and -2.6 . These genes are known to be transcriptionally regulated by Car (official symbol Nrli3), which we previously postulated to be an important transcription factor affected by quercetin supplementation (Hoek-van den Hil et al. 2013). The top regulated genes $(p<0.01$ and absolute fold change $>1.5$ ) and confirmation of these genes by RT-qPCR are shown in Table 2. This list includes another cytochrome P450 and two genes involved in lipid metabolism: fatty acid binding protein 5 (Fabp5) and hydroxyacid oxidase 2 (Hao2).

\section{Discussion}

This study shows that quercetin attenuated the increase of circulating lipids, hepatic lipid accumulation, and body weight gain, all dietary risk factors for CVD, caused by a chronic high-fat diet. These effects of quercetin were accompanied by regulation of cytochrome P450s.

The significant lower body weight gain of mice induced by high-fat diet upon $0.33 \%$ quercetin supplementation cannot be explained by a lower food intake or higher faecal energy losses. The quercetin fed mice gained less weight with a similar digestible energy intake resulting in a 
Table 2 Top regulated genes from microarray analysis in liver with an absolute fold change $>1.5$ and $p<0.01$

\begin{tabular}{|c|c|c|c|c|c|c|}
\hline \multirow[t]{2}{*}{ Gene symbol } & \multirow[t]{2}{*}{ Gene name } & \multirow[t]{2}{*}{ Accession number } & \multicolumn{2}{|c|}{ Microarray } & \multicolumn{2}{|c|}{ RT-qPCR } \\
\hline & & & $\mathrm{FC}$ & $p$ & $\mathrm{FC}$ & $p$ \\
\hline Csad & Cysteine sulphinic acid decarboxylase & NM_144942 & 2.33 & 0.0045 & 2.73 & 0.001 \\
\hline$C i b 3$ & Calcium and integrin binding family member 3 & NM_001080812 & 1.88 & 0.0004 & n.a. & \\
\hline Fabp5 & Fatty acid binding protein 5 , epidermal & NM_010634 & 1.59 & 0.0075 & 1.37 & 0.173 \\
\hline Tfrc & Transferrin receptor & NM_011638 & 1.52 & 0.0069 & 1.45 & 0.016 \\
\hline Сур3а59 & Cytochrome P450, subfamily 3 a59 & NM_001105160 & -1.51 & 0.0038 & n.a. & \\
\hline Hao2 & Hydroxyacid oxidase 2 & NM_019545 & -1.67 & 0.0022 & -2.81 & 0.006 \\
\hline Cур $2 b 9$ & Cytochrome P450, family 2 b9 & NM_010000 & -2.30 & 0.0009 & -8.2 & 0.0003 \\
\hline Cyp $2 b 13$ & Cytochrome P450, family $2 \mathrm{~b} 13$ & NM_007813 & -2.39 & 0.0006 & n.a. & \\
\hline Cyp $2 b 10$ & Cytochrome P450, family $2 \mathrm{~b} 10$ & NM_009999 & -2.63 & 0.0028 & n.a. & \\
\hline
\end{tabular}

Not assigned probes were not mentioned in the table; NAP111439-1 (FC $=1.64, p=0.009)$, NAP114472-1 (FC = 1.59, $p=0.007)$, Gm10804 $(\mathrm{FC}=-1.83, p=0.0069)$, A_55_P2071906 $(\mathrm{FC}=-1.9, p=0.002)$. Fold changes are depicted as the expression values of quercetin over control animals. $F C$ fold change, $p$ p value; $n . a$. not assessed

significantly lower calculated food efficiency. The high-fat (40 en\%) diet induced body weight gain and hepatic lipid accumulation. In case of a normal fat (10 en\%) diet, body weight gain over 12 weeks was $40-50 \%$ of the body weight gain by high-fat diet feeding (Hoevenaars et al. 2013; Voigt et al. 2013). The observed body weight gain in mice fed the high-fat diet supplemented with quercetin was lowered with $29 \%$ compared to high-fat diet feeding, thus decreasing it towards a more normal level. Hepatic lipids level after normal fat feeding for 12 weeks was only around $4 \%$ of the value after high-fat feeding and the highfat supplemented with quercetin decreased the hepatic lipid level to $27 \%$ of the high-fat values. Both parameters show that quercetin supplementation reduced the effects of the high-fat diet substantially, changing these parameters into the direction of values that are observed upon a more normal healthy (10 en\%) fat diet.

Our results were in line with other studies performed with supplementation of 0.025 and $0.05 \%$ quercetin to 40 en\% high-fat diets (Jung et al. 2013; Kobori et al. 2011), which also resulted in lowering of body weight gain and hepatic lipid accumulation. Other studies with doses of quercetin ranging between 0.05 and $1 \%$ were shorter or used a diet with a lower energy $\%$ of fat. Consequently, body weight gain was lower in these studies and as a result, quercetin did not show a decrease in bodyweight gain (de Boer et al. 2006; Odbayar et al. 2006; Stewart et al. 2009; Wein et al. 2010). Our previous data (30 en\% fat diet) (Hoek-van den Hil et al. 2013) showed also no effects on body weight gain and hepatic lipid accumulation, which study was identical to the present study except for the used background diet. Taking this together, we conclude that the observed effects of quercetin on body weight gain and hepatic lipid accumulation are dependent on the en $\%$ fat in the diet. The magnitude of body weight gain and hepatic lipid accumulation caused by the diet, which is dependent on the dietary fat content, seems to be important for the outcomes obtained in these quercetin supplementation studies.

In our previous study, we have shown that quercetin induced hepatic lipid $\omega$-oxidation and lowered corresponding serum triglyceride levels, possibly under transcriptional control of CAR (Hoek-van den Hil et al. 2013). These specific changes in serum triglyceride levels and genes involved in lipid $\omega$-oxidation were not seen in the present study, which also suggests an influence of the used diet on these effects. Omega-oxidation is known to be induced by a high-fat diet and in case of induced nonalcoholic fatty liver disease (Hardwick 2008). Here, the highfat diet induced a fatty liver, thus $\omega$-oxidation and especially Cyp $4 a$ transcripts are expected to be upregulated, already in the high-fat control group, possibly diminishing further stimulation by quercetin.

Whole genome microarray analysis of liver revealed that Cyp2b9, Cyp2b10, and Cyp2b13 were the most evident genes regulated by quercetin. These three genes comprise the hepatic cyp $2 b$ genes of mice. Besides metabolism of endogenous and xenobiotic compounds, cytochrome P450s are also important in hepatic lipid homoeostasis (Sueyoshi et al. 1999). Importantly, these Cyp $2 b$ genes are known to be under control of CAR (Honkakoski et al. 1998; Sueyoshi et al. 1999). Thus, although differences in liver gene expression are seen in this study compared to our previous study (Hoek-van den Hil et al. 2013), in both cases lipid metabolizing genes that are under control of CAR were modulated, and the changes were accompanied by changes in serum lipids.

CAR is involved in the regulation of genes which are involved in lipid homoeostasis. CAR mediates the induction of cytochrome P450 enzymes, including Cyp 2 b10, 
dietary linoleic acid is shown to be a regulator of $\mathrm{P} 450$ expression via CAR (Finn et al. 2009). Linoleic acid is also abundantly present in the high-fat diet used in the present study, at double the amount compared to our previous study (supplementary table S1). Fabp5, the fourth gene among the top upregulated genes $(p<0.01)$ with a fold change of 1.59, can bind and transport long-chain fatty acids and it has a high affinity for linoleic acid (Ogawa et al. 2011). This may suggest that linoleic acid transport into the liver of quercetin fed animals is increased. Furthermore, activation of CAR as well as induction of Cyp2b mRNA by the known inducer phenobarbital can be attenuated by PUFAs ( $\mathrm{Li}$ et al. 2006, 2007). Altogether, this information suggests that possible activation of CAR by quercetin can be possibly attenuated by dietary linoleic acid. Although this has to be further investigated in detail, our results indicate that it is important to take the composition of the dietary background into account in evaluation effects of quercetin and, most likely, of other polyphenols. Indeed, also for the polyphenol resveratrol, marked differences in functional effects were observed dependent on standard or high-fat dietary backgrounds (Pearson et al. 2008).

In conclusion, high-fat diet induced hepatic lipid accumulation, circulating lipids and weight gain were reduced by chronic intake of quercetin in mice. Also cytochrome $\mathrm{P} 450$ s were regulated in liver, which are under transcriptional control of the nuclear receptor CAR. Our data newly suggest that these effects may depend on dietary fat content and composition. This novel notion may provide an explanation for the apparent contradictions in the outcomes of studies with quercetin and potentially has important implications for the analysis and interpretation of human studies.

Acknowledgments We thank Marjanne van Vliet and colleagues from the animal facility for their help during the animal experiment and Tom Amolo for his help with the histological stainings. This research was financially supported by graduate school VLAG. J. Keijer is a member of the European Union COST Action FA1403 (POSITIVe).

Conflict of interest E.F. Hoek-van den Hil, E.M. van Schothorst, I. van der Stelt, H.J.M. Swarts, D. Venema, M. Sailer, J. Vervoort, P.C.H. Hollman, I.M.C.M. Rietjens, J. Keijer declare that they have no conflict of interest.

Ethical standard All institutional and national guidelines for the care and use of laboratory animals were followed.

\section{References}

Arts IC, Hollman PC (2005) Polyphenols and disease risk in epidemiologic studies. Am J Clin Nutr 81:317S-325S
Boden G (2008) Obesity and free fatty acids. Endocrinol Metab Clin North Am 37:635-646

Bustin SA, Benes V, Garson JA, Hellemans J, Huggett J, Kubista M, Mueller R, Nolan T, Pfaffl MW, Shipley GL, Vandesompele J, Wittwer CT (2009) The MIQE guidelines: minimum information for publication of quantitative real-time PCR experiments. Clin Chem 55:611-622. doi:10.1373/clinchem.2008.112797

de Boer VC, van Schothorst EM, Dihal AA, van der Woude H, Arts IC, Rietjens IM, Hollman PC, Keijer J (2006) Chronic quercetin exposure affects fatty acid catabolism in rat lung. Cell Mol Life Sci 63:2847-2858. doi:10.1007/s00018-006-6316-z

Finn RD, Henderson CJ, Scott CL, Wolf CR (2009) Unsaturated fatty acid regulation of cytochrome $\mathrm{P} 450$ expression via a CARdependent pathway. Biochem J 417:43-54. doi:10.1042/BJ200 80740

Harchaoui KE, Visser ME, Kastelein JJ, Stroes ES, Dallinga-Thie GM (2009) Triglycerides and cardiovascular risk. Curr Cardiol Rev 5:216-222. doi:10.2174/157340309788970315

Hardwick JP (2008) Cytochrome P450 omega hydroxylase (CYP4) function in fatty acid metabolism and metabolic diseases. Biochem Pharmacol 75:2263-2275. doi:10.1016/j.bcp.2008.03. 004

Hertog MG, Feskens EJ, Hollman PC, Katan MB, Kromhout D (1993) Dietary antioxidant flavonoids and risk of coronary heart disease: the Zutphen Elderly Study. Lancet 342:1007-1011

Hoek-van den Hil EF, Beekmann K, Keijer J, Hollman PC, Rietjens IM, van Schothorst EM (2012) Interference of flavonoids with enzymatic assays for the determination of free fatty acid and triglyceride levels. Anal Bioanal Chem 402:1389-1392. doi:10. 1007/s00216-011-5563-5

Hoek-van den Hil EF, Keijer J, Bunschoten A, Vervoort JJM, Stankova B, Bekkenkamp M, Herreman L, Venema D, Hollman PCH, Tvrzicka E, Rietjens IMCM, van Schothorst EM (2013) Quercetin induces hepatic lipid omega-oxidation and lowers serum lipid levels in mice. PloS One 8. doi:10.1371/journal. pone. 0051588

Hoevenaars FP, Keijer J, Swarts HJ, Snaas-Alders S, BekkenkampGrovenstein M, van Schothorst EM (2013) Effects of dietary history on energy metabolism and physiological parameters in C57BL/6 J mice. Exp Physiol 98:1053-1062. doi:10.1113/ expphysiol.2012.069518

Hollman PC, Geelen A, Kromhout D (2010) Dietary flavonol intake may lower stroke risk in men and women. J Nutr 140:600-604. doi:10.3945/jn.109.116632

Honkakoski P, Zelko I, Sueyoshi T, Negishi M (1998) The nuclear orphan receptor CAR-retinoid $\mathrm{X}$ receptor heterodimer activates the phenobarbital-responsive enhancer module of the CYP2B gene. Mol Cell Biol 18:5652-5658

Jouven X, Charles MA, Desnos M, Ducimetiere P (2001) Circulating nonesterified fatty acid level as a predictive risk factor for sudden death in the population. Circulation 104:756-761

Jung CH, Cho I, Ahn J, Jeon TI, Ha TY (2013) Quercetin reduces high-fat diet-induced fat accumulation in the liver by regulating lipid metabolism genes. Phytotherapy Res 27:139-143. doi:10. $1002 /$ ptr.4687

Kobori M, Masumoto S, Akimoto Y, Oike H (2011) Chronic dietary intake of quercetin alleviates hepatic fat accumulation associated with consumption of a Western-style diet in C57/BL6 J mice. Mol Nutr Food Res 55:530-540. doi:10.1002/mnfr.201000392

Li CC, Lii CK, Liu KL, Yang JJ, Chen HW (2006) n-6 and n-3 polyunsaturated fatty acids down-regulate cytochrome P-450 2B1 gene expression induced by phenobarbital in primary rat hepatocytes. J Nutr Biochem 17:707-715. doi:10.1016/j.jnutbio. 2005.12.003

Li CC, Lii CK, Liu KL, Yang JJ, Chen HW (2007) DHA downregulates phenobarbital-induced cytochrome P4502B1 gene 
expression in rat primary hepatocytes by attenuating CAR translocation. Toxicol Appl Pharm 225:329-336. doi:10.1016/j. taap.2007.08.009

Mink PJ, Scrafford CG, Barraj LM, Harnack L, Hong C-P, Nettleton JA, Jacobs DR (2007) Flavonoid intake and cardiovascular disease mortality: a prospective study in postmenopausal women. Am J Clin Nutr 85:895-909

Odbayar TO, Badamhand D, Kimura T, Takashi Y, Tsushida T, Ide T (2006) Comparative studies of some phenolic compounds (quercetin, rutin, and ferulic acid) affecting hepatic fatty acid synthesis in mice. J Agric Food Chem 54:8261-8265. doi:10. 1021/jf061135c

Ogawa E, Owada Y, Ikawa S, Adachi Y, Egawa T, Nemoto K, Suzuki K, Hishinuma T, Kawashima H, Kondo H, Muto M, Aiba S, Okuyama R (2011) Epidermal FABP (FABP5) regulates keratinocyte differentiation by 13(S)-HODE-mediated activation of the NF-kappa B signaling pathway. J Invest Dermatol 131: 604-612. doi:10.1038/Jid.2010.342

Pearson KJ, Baur JA, Lewis KN, Peshkin L, Price NL, Labinskyy N, Swindell WR, Kamara D, Minor RK, Perez E, Jamieson HA, Zhang Y, Dunn SR, Sharma K, Pleshko N, Woollett LA, Csiszar A, Ikeno Y, Le Couteur D, Elliott PJ, Becker KG, Navas P, Ingram DK, Wolf NS, Ungvari Z, Sinclair DA, de Cabo R (2008) Resveratrol delays age-related deterioration and mimics transcriptional aspects of dietary restriction without extending life span. Cell Metab 8:157-168. doi:10.1016/j.cmet.2008.06.011

Pellis L, Franssen-van Hal NL, Burema J, Keijer J (2003) The intraclass correlation coefficient applied for evaluation of data correction, labeling methods, and rectal biopsy sampling in DNA microarray experiments. Physiol Genomics 16:99-106. doi:10. 1152/physiolgenomics.00111.2003

Sailer M, Dahlhoff C, Giesbertz P, Eidens MK, de Wit N, RubioAliaga I, Boekschoten MV, Muller M, Daniel H (2013) Increased plasma citrulline in mice marks diet-induced obesity and may predict the development of the metabolic syndrome. PLoS ONE 8:e63950. doi:10.1371/journal.pone.0063950

Scorletti E, Calder PC, Byrne CD (2011) Non-alcoholic fatty liver disease and cardiovascular risk: metabolic aspects and novel treatments. Endocrine 40:332-343. doi:10.1007/s12020-0119530-x

Stewart L, Wang Z, Ribnicky D, Soileau J, Cefalu W, Gettys T (2009) Failure of dietary quercetin to alter the temporal progression of insulin resistance among tissues of C57BL/6 J mice during the development of diet-induced obesity. Diabetologia 52:514-523. doi:10.1007/s00125-008-1252-0

Sueyoshi T, Kawamoto T, Zelko I, Honkakoski P, Negishi M (1999) The repressed nuclear receptor CAR responds to phenobarbital in activating the human CYP2B6 gene. J Biol Chem 274: 6043-6046. doi:10.1074/jbc.274.10.6043

Targher G, Day CP, Bonora E (2010) Risk of cardiovascular disease in patients with nonalcoholic fatty liver disease. New Engl J Med 363:1341-1350. doi:10.1056/NEJMra0912063

van Schothorst EM, Pagmantidis V, de Boer VC, Hesketh J, Keijer J (2007) Assessment of reducing RNA input for Agilent oligo microarrays. Anal Biochem 363:315-317. doi:10.1016/j.ab. 2007.01.016

van't Veer P, Jansen MC, Klerk M, Kok FJ (2000) Fruits and vegetables in the prevention of cancer and cardiovascular disease. Public Health Nutr 3:103-107

Voigt A, Agnew K, van Schothorst EM, Keijer J, Klaus S (2013) Short-term, high fat feeding-induced changes in white adipose tissue gene expression are highly predictive for long-term changes. Mol Nutr Food Res 57:1423-1434. doi:10.1002/mnfr. 201200671

Wein S, Behm N, Petersen RK, Kristiansen K, Wolffram S (2010) Quercetin enhances adiponectin secretion by a PPAR-gamma independent mechanism. Eur J Pharm Sci 41:16-22. doi:10. 1016/j.ejps.2010.05.004 